\title{
TIPOLOGIA E DISTRIBUIÇÃO DOS PROCESSOS EROSIVOS NA MICROBACIA DO RIBEIRÃO ÁGUA DA CACHOEIRA, EM PARAGUAÇU PAULISTA, SP(1)
}

\author{
E. N. DOMINGUES ${ }^{(2)}$, M. ROSSI (3), I. F. A. MATTOS ${ }^{(4)}$, \\ K. ABE ${ }^{(5)} \& M . K^{\prime T A D A}{ }^{(5)}$
}

\begin{abstract}
RESUMO
Realizaram-se o levantamento, a caracterização e o mapeamento da erosão, com o objetivo de definir a tipologia e a distribuição dos processos erosivos predominantes na mi crobacia do ribei rão Água da Cachoeira, com aproximadamente 3.700 ha, localizada no Planalto Ocidental Paulista. Através da fotointerpretação e de trabal hos de campo, deli mitaram-se áreas com erosão laminar, erosão lami nar e sulco raso, erosão em sulco profundo e ravina, e erosão em ravina profunda e voçoroca. Foram mapeadas quatro grandes voçorocas conectadas à rede de drenagem, oito extensas ravi nas parcialmente vegetadas e diversas ravinas médias obliteradas, porém instáveis pela retomada da erosão. Há predominância de sulcos profundos e ravinas nas baixas vertentes em contato com a baixada fluvial e no talvegue das principais bacias de captação da drenagem pluvial. A origem de parte das ocorrências de sulcos rasos e de sulcos extensos, nas altas vertentes, é atri buída ao pisoteio do gado e, nas bai xas vertentes, às áreas de bebedouros. As interpretações finais indicaram quatro grupos de áreas, distintas pelas diferenças de tipos de processos erosivos e pela sua localização.
\end{abstract}

Termos de indexação: microbacia hidrográfica; áreas degradadas; tipologia de erosão; erosão laminar; sulcos; ravinas; voçorocas; mapeamento.

\section{SUMMARY: TYPOLOGY AND DISTRIBUTION OF EROSION PROCESSES IN A MICROWATERSHED OF THE RIBEIRÃO ÁGUA DA CACHOEIRA FROM PARAGUAÇÚ PAULISTA, SÃO PAULO STATE, BRAZIL}

With the objective of defining the typology and distribution of the predominant erosion processes in a "Água da Cachoeira" microwatershed, with 3.700 ha, located in the "Planal to

\footnotetext{
(1) Trabalho realizado sob o Convênio SMA-IFJ ICA e apresentado no 1o Simpósio Nacional de Geomorfologia, U berlândia (MG), 25 a 28 de novembro de 1996. Recebido para publicação em fevereiro de 1997 e aprovado em janeiro de 1998.

(2) Pesquisadora Científica do Instituto Florestal. Caixa Postal 1322, CEP 01051-970 São Paulo (SP). Bolsista do CNPq.

(3) Pesquisador Científico do Instituto Agronômico de Campinas. Caixa Postal 28, CEP 13001-970 Campinas (SP).

(4) Geógrafo, Instituto Florestal. Caixa Postal 1322, CEP 01051-970 São Paulo (SP).

(5) Pesquisador, Forestry and Forest Products Research Institute. PO Box 16, Norin Tsukuba, I baraki 305, J apan.
} 
Ocidental Paulista", a survey, characterization and mapping of erosion was conducted. Areas with shet erosion, shet and rill erosion, deep rill and gully erosion, and badlands weredelimited through photointerpretation and field work. Four large badlands connected to the drainage net, eight wide gullies with partial vegetation cover and several average gullies which were obliterated, but showed signs of retroerosion, were mapped. There is a predominance of deep rills and gullies in thelow slopes in contact with thefluvial plan and in themain basin slopeof the pl uvial drainageimpounding. Theorigin of thepart of theoccurrence of shallow rills and of thewiderills, in thehigh sl ope, is dueto cattletrampling and, in thel ow slope, can beattributed to the place of cattle-watering. The final interpretation showed four distinct classes, differing from another by thetype and areas of occurrence of the erosion processes.

Index terms: degraded microwatershed; erosion typology; sheet erosion; rill erosion; gullies; badlands; mapping.

\section{INTRODUÇÃO}

A ocupação e a colonização do oeste paulista provocaram o desmatamento quase total de sua vegetação natural, provocando maior suscetibilidade das vertentes, que atingiram al to grau de fragilidade, em decorrência de práticas agrícolas empíricas e ultrapassadas, isto é, de exploração indevida dos recursos, sem planejamento e conhecimento de suas reais possi bilidades, fazendo da erosão um fenômeno comum nesta região, ocasionando a perda detoneladas de sol o por ano, a alteração da qualidade equantidade de água e a sedimentação dos cursos d'água. Atualmente, nessa região, a chuva concentrada de média intensi dade provoca inundações, assoreamento de reservatórios, destruição de pontes e plantações, com altos prejuízos naturais e sócio-econômicos.

Tais problemas, antes vistos como locais e de responsabilidadeindividual de proprietários, passam a ter uma visão mais regional, quando os recursos hídricos mostram sinais de deterioração, trechos de áreas urbanas começam a ser destruídos com o avanço de grandes voçorocas, partes de rodovias passam a apresentar problemas mais sérios deerosão, ediversas barragens e reservatórios começam a ser assoreados, alguns até destruídos, confirmando-se a necessidade urgente, não só de conter a degradação, mas também de entender e avaliar localmente os mecanismos desses processos. No que se refere à evolução da erosão, Tricart (1966) ressaltou que ocorrem descontinuidades temporais e espaciais dos processos de evolução do rel evo, razão por que um mesmo local pode estar, por algum tempo, sob maior ação dos processos erosivos, alternados por períodos de predominância de processos de acumulação.

Ab'Saber (1968) salientou que a friabilidade e as condições dealteração superficial esubsuperficial dos arenitos paleozói cos ou mesozóicos são fatores de fragilidade, sendo as voçorocas neles desenvolvidas mais agressivas, isto é, de evolução muito rápida.

A perda de resistência ou estabilidade e o desarranjo da estrutura do solo são causados pela força de percol ação da água em seu interior, conhecida como processo de rupturas hidráulicas. Esse processo promove a retroerosão, ou erosão regressiva, que tem início em um ponto de emergência d'água e progride para montante, carreando os sedi mentos das camadas internas do sol o pela ação do escoamento subsuperficial eformando espaços vazios interligados, denominados tubos de erosão ou processo de "pi ping" (Vargas, 1977). Salomão (1994) e Coel ho Netto (1995) ressaltaram a importância das características do solo, como a porosidade, no desenvolvimento desse processo, que tem origem, muitas vezes, em zonas de descontinuidades litológicas eno uso incorreto do solo.

Buraczynski (1983) afirmou que as atividades econômicas ea propriedade de resistência do sol o são fatores fundamentais sobrea er osão equetambém as variáveis estrutura geol ógica, preci pitação e cobertura vegetal diferenciam as características de dimensão das formas ou cicatrizes erosivas.

As alterações introduzidas nos ambientes naturais resultam do esforço ou tensão ao qual o sistema é submetido e de seu grau de suscetibilidade às mudanças impostas, promovendo um processo de reajuste em torno do equilíbrio dinâmico oscilante (Drew, 1989). Queiroz Netoet al . (1977) indicaram uma fase recente de instabilização na região de Marília, iniciada com o desmatamento, e constataram, em 1973, que as erosões em sulcos profundos e voçorocas persistiam na paisagem, mas os sul cos menores foram obturados por sedimentos.

Os processos erosivos, segundo Bertoni \& Lombardi Neto (1990), são decorrentes de fatores, tais como: pluviosidade, declividade, comprimento do dedive, capacidade de absorção da água pel o sol o, resistência do solo à erosão e densidade da cobertura vegetal. A água é o mais importante agente erosivo, e o escoamento concentrado ocasiona ental hamentos profundos, bem como o movimento de grandes massas de solo. Guerra (1995) acrescentou que a circulacão da água de infiltração agrava os problemas de sulcos e voçorocas, e São Paulo (1990) ressaltou que o substrato rochoso é um dos el ementos que favorecem a erosão acelerada.

São Paulo (1990) classificou as "voçor ocas", quanto à origem, em dois grupos: as produzi das por distúrbios hidrológicos, demaior portee ramificadas (escoamento 
subsuperficial), e as produzidas pelo escoamento superficial concentrado urbano (águas pluviais e servidas) e rural (drenagem de rodovias e manejo do solo), motivadas pel o fator uso do solo.

Já Oliveira (1995) sistematizou-as em: (a) conectadas à rede de drenagem com processos de filetes subverticais hierarquizados, liqüefação espontânea, descolamento de fendas detração, erosão por infiltração ou afloramento do lençol freático, "piping", erosão pluvial-sal pico, escoamento difuso e concentrado no interior e nas bordas da voçoroca e movimentos de massa localizados; (b) desconectadas, enfatizando processos de movimentos de massa e escoamento superficial; (c) a integração dos diversos mecanismos citados.

Segundo Guerra (1995), o escoamento superficial difuso produz a erosão laminar, muitas vezes mais drástica do que as outras formas de erosão, como as ravinas e voçorocas: as ravinas, incisões obliteráveis por máquinas agrícolas, e as voçorocas, incisões que impedem o trabal ho de máquinas. Quanto à origem, as voçorocas podem surgir por retrabal hamento do escoamento superficial concentrado, em antigas cicatrizes de deslizamentos de terra, ou de escorregamentos.

Este estudo faz parte do "Programa de Pesquisa em Conservação de F loresta e do M eio Ambiente", em desenvol vimento pelo I nstituto Florestal e pela "J apan International Coorporation Agency", que visa a uma política eficaz de preservação e de recuperação de áreas degradadas, fundamentado em bases técnicocientíficas.

Como objetivos, buscou-se reconhecer e classificar as diversas formas de erosão existentes na microbacia, suas principais características e áreas de ocorrência, em relação aos diferentes mi cro emacrocompartimentos do relevo e da rede de drenagem pluvial e fluvial. Anal isaram-se os resultados através de uma proposta deinterpretação conjunta entretipol ogia edistribuição das erosões: lineares e laminares, como subsídio ao planejamento de microbacias hidrográficas.

\section{MATERIAL E MÉTODOS}

A microbacia do ribeirão Água da Cachoeira com, aproximadamente, 3.700 ha, Iocaliza-seno município de Paraguaçu Paulista, no sudoeste do E stado de São Paulo, entre 22ㅇ 17' e 22을 23 'de latitude sul e 50 $35^{\prime} \mathrm{e}$ 50 o 37'de longitude oeste de Grws., em altitudes de 420 a 610 m (Figura 1 ).

O relevo do Planalto Ocidental Paulista, regionalmente é constituído por colinas médias e col inas amplas, compreendendo rochas areníticas do Grupo Bauru, caracterizado pel as Formações Marília eAdamantina (Almeida, 1974; IPT, 1981a,b).

A vegetação original era constituída pela Floresta Estacional Semidecidual e por Cerrados, em solos do tipo Latossol o Vermel ho-E scuro e Podzól i co Vermel hoAmarelo. Caracteriza-se por clima do tipo Cwa (Köppen), quente com inverno seco, temperatura máxima em torno de ${ }^{30} \mathrm{C}$ e mínima de ${ }^{\circ} 0^{\circ} \mathrm{C}$, podendo ocorrer geadas, apresentando chuvas concentradas nos meses de dezembro a março, com cerca de $1.480 \mathrm{~mm}$ ano $^{-1}$.

Foram utilizadas fotografias aéreas verticais pancromáticas, na escala aproximada de 1:20.000, executadas pela Base Aerofotogrametria e Projetos S/A, na região de Paraguaçu Paulista, ConvênioSMAIF/J ICA, 1993, e a carta topográfica do IBGE, de 1973, Folha de Paraguaçu Paulista na escala de 1:50.000, SF-22-Z-A-I-4.

Do ponto de vista metodológico, reconheceu-se a microbacia hidrográfica como uma unidade de paisagem representativa para os estudos do meio físico, rel aci onados com sua caracterização e avaliação da presença de processos de evolução acelerada das vertentes.

Realizaram-se a classificação e a distribuição das cicatrizes ou marcas erosivas, baseadas nos princípios conceituais de J ahn (1968), enfatizando a análise do ponto de vista da predominância dos processos lineares, relacionados com o aprofundamento das

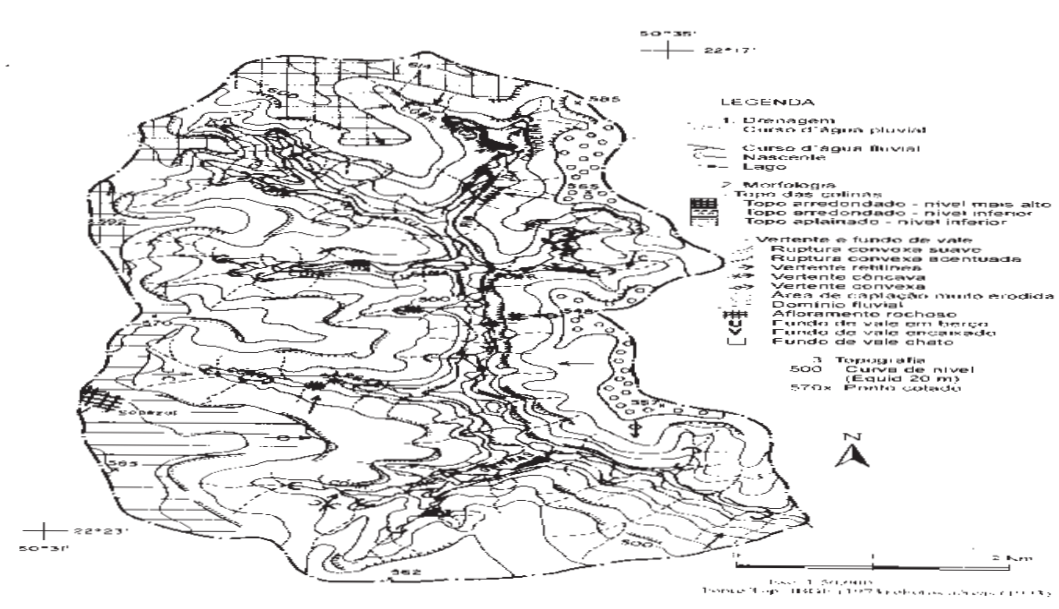

Figura 1. Localização da microbacia do ribeirão Água da Cachoeira, Planalto Ocidental Paulista. 
superficies erodidas e com os indícios da erosão laminar, ou seja, sem incisões significativas na superfície do solo.

Os critérios adotados foram defini dos com base na fotointer pretação (parâmetros visuais e morfométricos) e apoiaram-se nas características das cicatrizes ou feições erosivas existentes, através de seus contornos, largura, ramificações, extensão, direção, disposição, localização e conexão, com referência à drenagem e ao relevo.

Elaborou-se o mapa da rede de drenagem e dos elementos morfológicos principais, através da fotointerpretação e trabal hos de campo (período 1993 a 1995), com dados referentes aos canais de escoamento fluvial ou permanente e canais pluviais ou temporários e esporádicos (Strahler, 1957). Consideraram-se, também, os pontos ou áreas de nascentes, como dados fundamentais para as análises das cabeceiras das voçorocas edas ravinas. Definiramseas características morfológicas dos topos, vertentes e fundos de vales, ressaltando as principais descontinuidades do relevo, relacionadas com as interferências ou com os processos erosivos (Tricart, 1977; Queiroz Neto et al., 1977), apresentados na escala de 1:50.000.

Assim, com a fotoi nterpretação, os dados de campo e os subsídios bi bliográficos, foi possível identificar os locais com erosão de entalhe edistinguir as áreas com cicatrizes, ou seja, feições erosivas lineares das áreas sem ental hamentos ou com indicações de existência de filetes e erosão laminar, segundo procedimentos adaptados de Tricart (1977), Buraczynski (1983), Bertoni \& Lombardi Neto (1990) e Salomão (1994). Representaram-se os principais processos lineares individualmente em um mapa, e a distribuição dos aglomerados (lineares) e áreas com erosão laminar, em outro. N este, as áreas com erosão laminar local izadas nos compartimentos das al tas vertentes e nos topos largos, quase planos, foram del imitadas por exclusão quanto às incisões erosivas. Ambos os processos foram efetuados na escala de 1:50.000.

\section{RESULTADOS E DISCUSSÃO}

Na figura 2, éapresentado o mapa da drenagem e da morfologia do ribeirão Água da Cachoeira, que compõe drenagem de $4^{\mathrm{a}}$ ordem com cinco subbacias principais: a do córrego das Três Barras, do Sapezal, da Usina, da Bacia "A" e da Represa.

Considerando o vale principal, as vertentes fazem parte do conjunto de relevo de degradação em planaltos dissecados, envolvendo modelado local predominantemente erosivo e poucos setores de vales com processos de acumulação, em altitudes superiores a $450 \mathrm{~m}$.

Observou-se estreita associação entre as condições hidrográficas eas topomorfológicas da mi crobacia. $\mathrm{Na}$ porção oeste, os canais são mais desenvolvidos e ramificados, com divisores d'água secundários amplos e bem definidos, topos largos e chatos e rupturas de declives, predominantemente convexas suaves. Nas cabeceiras de drenagem dessas áreas, ocorrem as voçorocas e as maiores ravinas.

Na porção leste, os canais são mais curtos, pouco ramificados, com muitas rupturas de decl ive convexas acentuadas, topos mais arredondados, interflúvios secundários pouco pronunciados, imprimindo maior declividade das baixas vertentes, apresentando-se o canal principal mais encaixado. Essas vertentes possuem direção predominante para a cal ha do ribei rão Água da Cachoeira, percebendo-se, no médio curso, vertentes retilíneas de menor comprimento de rampas, com canais pluviais retos esem rami ficações (Figura 2).

Existe, portanto, um aspecto morfoestrutural associado à drenagem e às feições erosivas lineares, constatado nessas rupturas e caracterizando, também, encaixe do fundo de vale e afloramentos rochosos, conforme observou Sal omão (1994). Os diferentes tipos de fei ções erosivas, bem como a distribuição das ár eas mais significativas com erosão linear (Figuras 3 e 4), estão, em parte, na dependência desses fatores do rel evo e do escoamento superficial, concordando com Tricart (1966).

A erosão laminar, com a remoção em lençol das camadas superficiais do solo, é processada de forma bastante intensa em toda a microbacia, como conseqüência da degradação generalizada. No entanto, as áreas de domínio da erosão laminar ocorrem nas altas vertentes e topos (Figuras 3 e 4). Tal fato, apesar de pouco perceptível nos locais de erosão, conforme ressaltaram Bertoni \& Lombardi Neto (1990) eGuerra (1995), com o rebaixamento quase homogêneo das superficies, é notado nas áreas planas das baixadas, onde, freqüentemente, após chuvas torrenciais, há o acúmulo repentino de espessos lençóis de areias, conforme também registraram em outras áreas do Planalto Ocidental Paulista Queiroz N eto et al. (1973 e 1977). Na microbacia, durante esses episódios freqüentes no verão, há o assoreamento das planícies mais largas e trechos dos canais fluviais.

A erosão em sulco raso (Figuras 3 e 4) predomina nas médias e altas vertentes em áreas de cultivo, princi pal mente de cana, nas baixas vertentes e perto de canais fluviais, em áreas de pastagens e nos locais de bebedouros. Há, ainda, degradação da cobertura do solo e grande densidade de sulcos, ravinas e voçorocas. Na subbacia do córrego Três Barras, os sulcos rasos longos e estreitos são bem distribuídos estendendo-se, em muitos locais, desde os topos até a baixada fluvial e relacionam-se com o caminhamento do gado.

Nas médias eal tas vertentes das bacias derecepção e nas margens de estradas, registrou-se maior freqüência da erosão em sulco profundo e ravina (Figuras 3 e 4), enquanto Sal omão (1994) encontrou maior densidade nas cabeceiras de drenagem. Comprovou-se a reinstalação dos processos erosivos em ravinas obliteradas, localizadas perto das cabeceiras de voçorocas. Em áreas com trabalho recente de máquinas eplantio de no máximo três anos, a silhueta de ravinas ao longo dos eixos de drenagem foi visível nas fotos, porém, no campo, observaram-se 


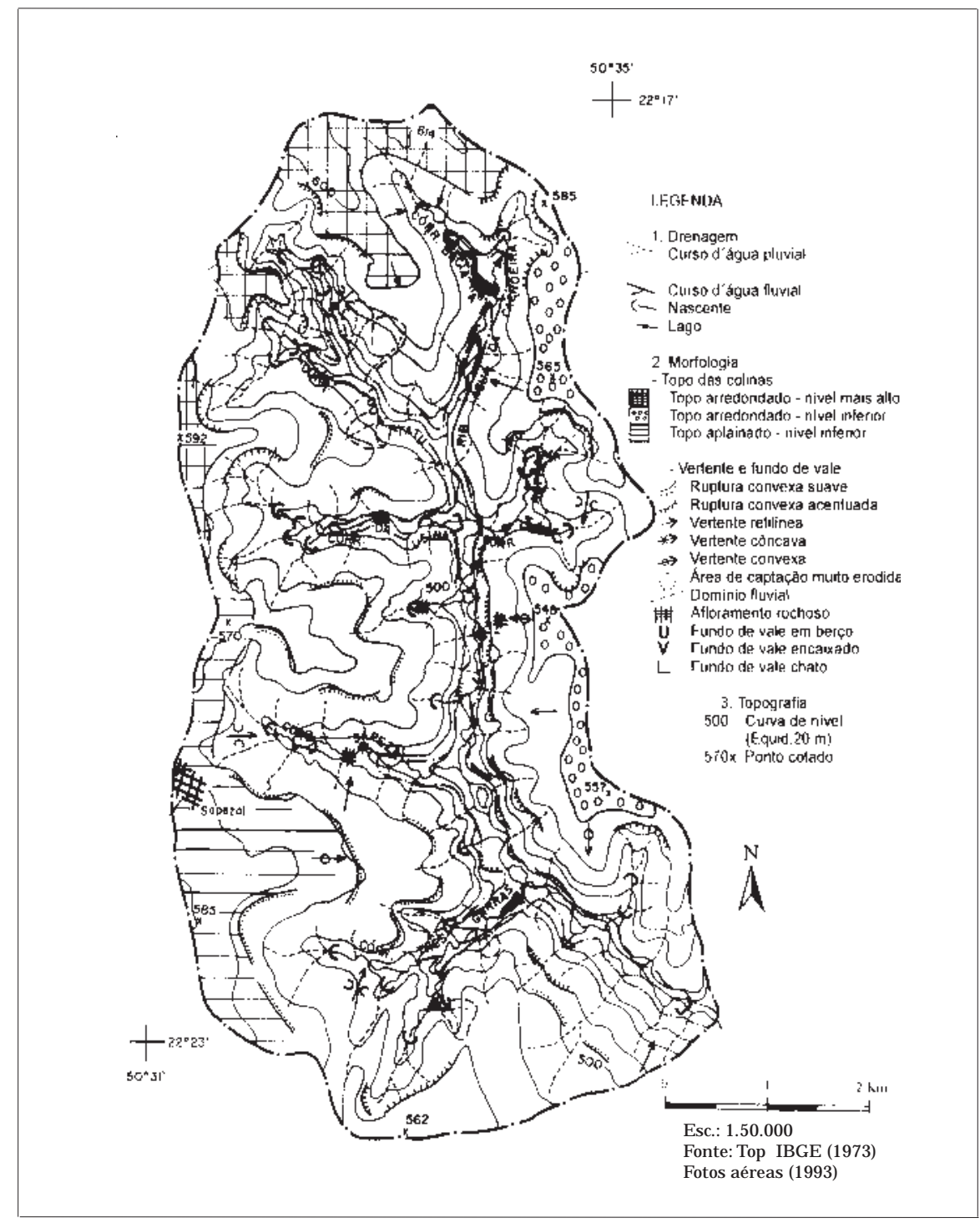

Figura 2. Topografia, drenagem e morfologia da microbacia do ribeirão Água da Cachoeira, em Paraguaçu Paulista (SP).

apenas pequenos terracetes e patamares de afundamentos descontínuos, associados ao escoamento superficial pluvial concentrado.

As voçorocas eas ravinas apresentaram diferenças que são comandadas não só pela drenagem e relevo, mas também pelas características dos solos, da dinâmica das precipitações, do uso atual e pretérito dosolo e dos demais fatores que comandam a dinâmica ambiental dessa área, o que concorda com São Paulo (1990), Oliveira (1995) e Coel ho Netto (1995), quando ressaltaram a importância dessas características na evolução dos processos erosivos.

Quanto às incisões em processo de voçorocamento, verifica-se que, mesmo sendo longitudinal ao canal, nem sempre ocorre a remoção do solo, tomando por base um talvegue ou vários talvegues convergentes para um principal. Há locais com predominância de processos erosivos superficiais, isto é, grande remoção desolo, mas ausência deincisões profundas. Reconhecese, portanto, que a voçoroca é resultante de processos incluídos na categoria de linear, mas há fases em que predomina or etrabalhamento marginal paralelo com maior remoção das camadas superficiais do solo, contra o aprofundamento e alargamento do canal principal que, nesses casos, evolui mais lentamente. Percebe-se, também, que as grandes voçorocas ocorrem, principal mente, nas cabeçeiras dos afluentes da margem direita do ribeirão Água da Cachoeira e que, ao longo do canal fluvial principal, ocorrem as voçor ocas não ramificadas.

Muitas voçorocas, mesmo não sendo ramificadas em várias cabeçeiras de retroerosão, apresentaram níveis de desbarrancamentos e rebaixamento da superficie marginal, em degraus diferentemente 


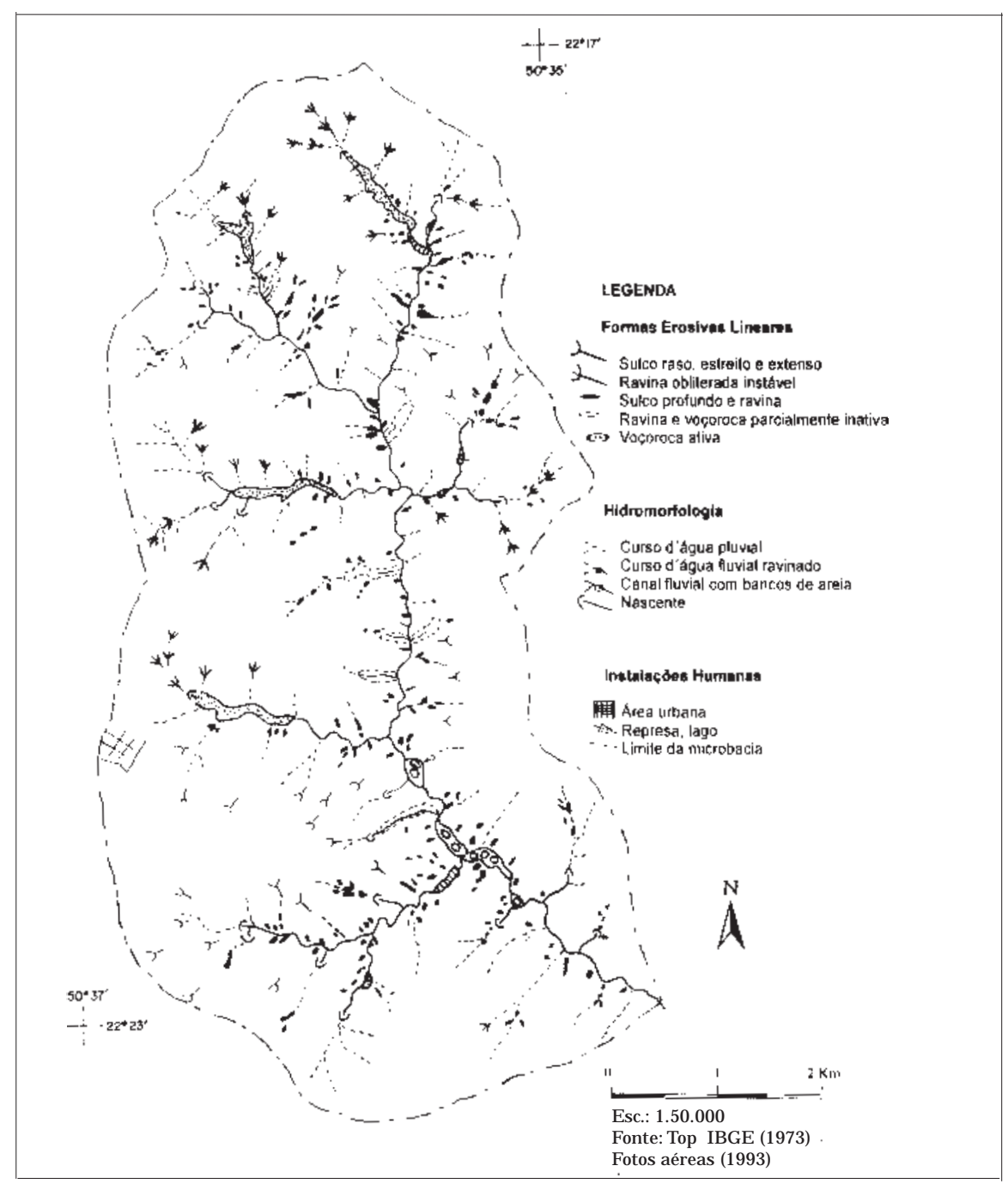

Figura 3. Levantamento da erosão linear na microbacia do ribeirão Água da Cachoeira (SP).

erodidos. Nessas áreas, há níveis de patamares formados por perda de solo, afundamentos e subsidências, onde persistem árvores de até $20 \mathrm{~m}$ de altura, arvoredos e arbustos. Assim também, em torno de um canal principal estreito e profundamente entalhado, em algumas áreas próximas às margens, ocorre maior ação da erosão laminar com processos de erosão superficial acentuados, concordando com Bertoni \& Lombardi Neto (1990).

Quanto ao tipo e distribuição das voçorocas, notase uma seqüência evolutiva alternada dos processos lineares e laminares em diferentes fases de sua formação, nãohavendo limites nítidos que os separam, predominando ora um, ora outro, como mencionou Tricart (1966, 1977), ao ressaltar as descontinuidades temporais e espaciais dos processos erosivos. Nessa área, grande parte das ravinas pode ser considerada como uma fase inicial de voçorocas, em virtude da predominância de ravinas próximas aos canais fluviais.
Considerando as ravinas como entalhamento resultante da ação restrita ligada aos processos de escoamento superficial, podendo ser obliteradas por máquinas agrícolas (Guerra, 1995) e que, nesta microbacia, as obliteradas compreendem cabeceiras de voçorocas, verifica-se que os processos estão intimamente interligados, havendo, assim, ravinas conectadas à rede de drenagem fluvial e ravinas desconectadas, associadas à redede drenagem pluvial . Estas originaram-se de processos antrópicos e pisoteio do gado e desenvolveram-se pela ação da erosão pluvial, isto é, através do impacto da chuva e do escoamento superficial concentrado.

Nas ravinas próximas aos canais fluviais, o termo desconectada da rede fluvial refere-se à ausência do escoamento perene ou conexão com lençol d'água subsuperficial e nelas não há o desenvolvimento dos processos de "pi ping", que caracterizam as voçorocas. Sugere-se, portanto, considerá-las como desconectadas apenas superficialmente, admitindo que a erosão 


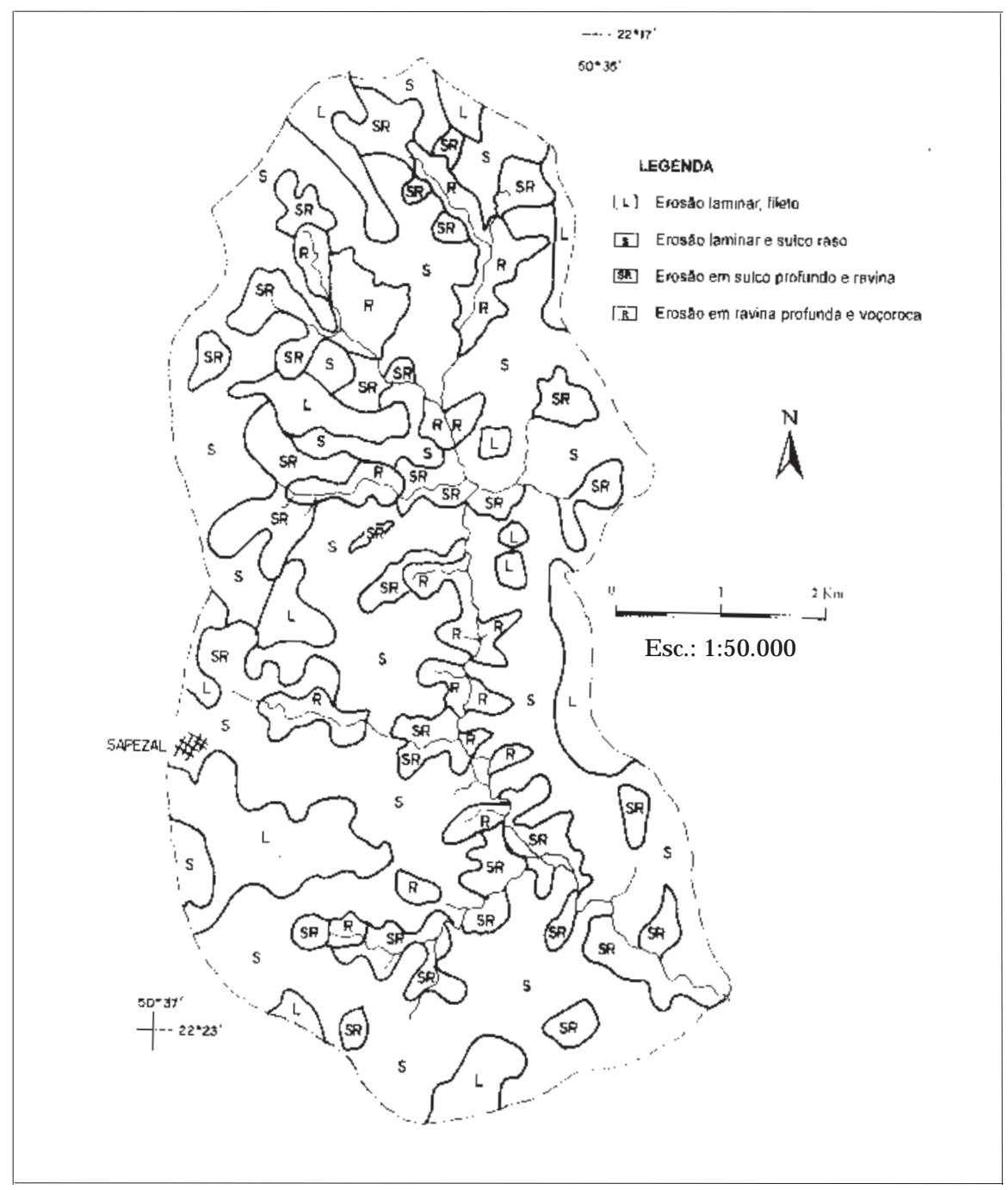

Figura 4. Classes de distribuição espacial das erosões lineares e laminares na microbacia do ribeirão Água da Cachoeira (SP).

laminar retal he a superficie, enquanto o "piping" escave a subsuperficie. Posteriormente, sua evolução poderá unir os mecanismos de superficie e de subsuperficie, conduzindo-as à categoria de voçoroca. Assim, as voçorocas têm origem no aprofundamento de uma ou várias ravinas, o que concorda com afirmações de Ab'Saber (1968). As interpretações dos resultados indicam que tal fato ocorrena mai oria das voçorocas dessa microbacia.

Registros de incisões erosivas ede demais processos erosivos são importantes para a caracterização das condições atuais e representam um momento da evolução histórica de degradação da área, embora não possam ser interpretados quanto aos aspectos quantitativos associados à dinâmica erosiva, corroborando as proposições de Buraczynski (1983).

Contudo, os resultados apontaram a ocorrência de duas voçorocas grandes, com, aproximadamente, 3 ha cada e uma média com 1 ha, num total de 7 ha de incisões lineares de grandes dimensões no al to curso. No trecho médio da microbacia, registraram-se duas voçorocas grandes ecinco médias, num total estimado de 11 ha, enquanto, notrecho final, foram encontradas duas voçorocas médias, ocupando 2 ha. Quanto aos sulcos profundos e ravinas, estimou-se em cento e noventa enove (199) cicatrizes, com área total de 47 ha ou 1,27\% da microbacia. Dos 3.700 ha da área, 66 ha são erosões lineares, isto é, superficies fortemente erodidas, abrangendo $1,72 \%$ da mi crobacia.

É importante ressaltar, ainda, que o manejo atual do solo é intenso na microbacia, e o seu freqüente preparo para o cultivo, principalmente de cana, desviou pequenas canaletas, entulhou sulcos, obl iterou ravinas eaté cabecei ras de grandes voçorocas, criando condições para que se instalasse a erosão, conforme destacaram Bertoni \& Lombardi N eto (1990) e Coel ho 
Netto (1995), acentuando as características de instabilidade, principalmente nas cabeceiras das grandes voçorocas, concordando com Vargas (1971, 1977).

A análise dos resultados através da proposta de interpretação conjunta entre tipol ogia e distribuição das erosões evidenciou zonas extremamente críticas quanto à ocorrência e predominância dos diferentes processos erosivos (lineares e areolar) localizadas nas baixas vertentes e ao longo dos canais fluviais principais (Figuras 3 e 4). As erosões lineares concentram-se nos solos tipo podzól icos com gradiente textural entre horizontes, sob pastagem e cultivo de cana-de-açúcar, e a laminar ocorre de maneira generalizada em toda a área. Esse método de estudos mostrou-se adequado, pois possibilitou indicar uma sistemática quanto à ocorrência da erosão acelerada da área permitindo ao planejador tomar medidas preventivas ou de recuperação da área.

\section{CONCLUSÕES}

1. A microbacia do ribeirão Água da Cachoeira, quanto à tipologia e distribuição dos processos erosivos, apresenta: áreas com erosão laminar, erosão laminar e sulco raso, erosão em sulco profundo e ravina, e erosão em ravina profunda e voçoroca.

2. As ravinas profundas e voçorocas associam-se às baixas vertentes retilíneas côncavas, próximas aos canais de drenagem fluvial, evidenciando zonas extremamente críticas quantoà predominância desses processos de formação.

3. Os sulcos profundos e ravinas distribuem-se em diferentes declividades ou segmentos de vertentes, tanto perto dos topos quanto perto das baixas vertentes no contato com a baixada fluvial e no talvegue das principais bacias de captação da drenagem pluvial. As ravinas anal isadas apresentam características visuais diferenciadas, atribuídas às diferentes fases de evolução e, possivelmente, às influências da intensidadee características do manejo do solo.

4. A erosão laminar e o sulco raso ocorrem indiferenciadamente em toda a microbacia, sendo mais visíveis nas médias e altas vertentes e topos estreitos. Os sulcos rasos aparecem com pequeno aumento de decl ividade e concentração do escoamento superficial. A origem de uma parte das ocorrências de sulcos rasos e de sulcos extensos, nas altas vertentes, éatribuída ao pisoteio do gado e, nas baixas vertentes, às áreas de bebedouros.

5. A erosão laminar apresenta-se distribuída de maneira generalizada em toda a microbacia e, principal mente, nos topos em áreas de cultivo, sendo de difícil distinção nas fotografias aéreas.

6. As características das feições erosivas indicam ser maior a remoção do solo nas áreas marginais aos canais fluviais, enquanto o canal evolui mais lentamente. Atualmente, em algumas voçorocas, dependendo de sua fase de evolução, há indícios de predominância de processos lineares e, em outras, de processo laminar.

7. Os sulcos erosivos ocorrem em diversos segmentos de vertentes, independentemente da morfologia, indicando que outras variáveis, exercem maior influência nos tipos e áreas preferenciais da formação dos sulcos profundos, como o uso atual do solo, as chuvas torrenciais e o escoamento concentrado. As rupturas de declives são mais acentuadas nas baixas vertentes e perto dos vales principais e influenciam a mudança de tipos de erosão.

8. Quanto às incisões mais significativas, dos 3.700 ha da microbacia, 66 ha compreendem áreas destruídas, com presença de erosões lineares de ravinamentos e voçorocamentos, representando 1,72\% da área estudada.

\section{LITE RATURA CITADA}

AB'SABER , A. N. As boçorocas de Franca. São Paulo, Fac. Filos. Ciênc. Letr. de Franca, 1968. 27p. (Separata da Revista da F.F.F.)

ALMEIDA, F.F.M. Fundamentos geológicos do relevo paulista. São Paulo, IGEOG/USP, 1974. (Série Teses e Monografias, 14)

BERTONI, J . \& LOMBARDI NETO, F. Conservação do solo. São Paulo, Í cone Coleção Brasil Agrícola, 1990. 355 p.

BURACZYNSKI, J. Les revins en tant qu'indice d'intensité de l'erosion par la fait de l'homme. In: COLÓQUIO ESTUDO E CARTOGRAFIA DE FORMAÇÕES SUPERFICIAIS E SUAS APLICAÇÕES EM REGIÕES TROPICAIS. São Paulo, 1983. Anais. São Paulo, FFLCH-USP, Dep. de Geografia, 1983. v.1. p.383-392.

COELHO NETTO, A.L. Mudanças ambientais recentes, mecanismos e variáveis - controle do voçorocamento atual na bacia do rio Bananal, SP-RJ : bases metodológicas para previsão e controle de erosão. In: SIMPÓSIO NACIONAL DE CONTROLE DE EROSÃO, 5., 1995, Bauru. Anais. Bauru, ABGE-UNESP, 1995. p.377-379.

DREW, D. Processos interativos homem-meio ambiente. 2 ed. Trad. J oão A. Santos. Bertrand Brasil, 1989. 206p.

GUERRA, A.J.T. Processos erosivos nas encostas. In: GUERRA, A.J .T. Geomorfologia uma atualização de bases e conceitos. 2ed. Rio de J aneiro, Bertrand Brasil, 1995. p.149-209.

INSTITUTO DE PESQUISASTECNOLÓGICAS DO ESTADO DE SÃO PAULO - IPT/SP. Mapa geomorfológico do Estado de São Paulo. São Paulo, Div. de Minas e Geol. Aplic., 1981a. v.1. (Monografias, 5)

INSTITUTO DE PESQUISASTECNOLÓGICAS DO ESTADO DE SÃO PAU LO - IPT/SP Mapa geológico do Estado deSão Paulo. São Paulo, Div. de Minas e Geol. Aplic., 1981b. v.1. 94p. (Monografias, 6)

J AHN, A. Denudational balance of slopes. Bull. Geographic Polonic, Geogr, Inst University of Wroclaw, 13:9-29, 1968. 
OLIVEIRA, M.A.T. Observação de marcas de erosão e cadastramento de voçorocas em meio rural. In: SIMPÓSIO NACIONAL DE CONTROLE DE EROSÃO, 5., Bauru, 1995. Anais. Bauru, ABGE-UNESP, 1995. p.253-255.

QUEIROZ NETO, J.P.; CARVALHO, A.; PELLERIN, J . \& J OURNAUX, A. Cronologia da alteração dos solos da região de Marília. São Paulo, Universidade de São Paulo, 1973. 55p.(Sedimentologia e Pedologia, 5)

QUEIROZ NETO, J.P.; J OURNAUX, A.; PELLERIN, 」. \& CARVALHO, A. Formações superficiais da região de Marília (SP). São Paulo, Universidade de São Paulo, 1977. 39p. (Sedimentologia e Pedologia, 8)

SALOMÃO, F.X.T. Processos erosivos lineares em Bauru (SP): regionalização cartográfica aplicada ao controle preventivo urbanoe rural. São Paulo, Universidade deSãoPaulo/FFLCH 1994. 200p. v.1 (Tese de Doutorado)
SÃO PAULO. Secretaria de Energia e Saneamento. Departamento de Águas e Energia Elétrica. Controle de Erosão: bases conceituais etécnicas; diretrizes para o planejamento urbano e regional; orientação para o controle de voçorocas urbanas. 2.ed. São Paulo, DAEE/IPT, 1990. 92p.

STRAHLER, A.N. Quantitative analyses of watershed geomorphology transaction. Am. Geoph. Union, New Haven, 38:913-920, 1957.

TRICART, J . As descontinuidades nos fenômenos da erosão. Not. Geomorf., Campinas, 6:3-14, 1966.

TRICART, J . E codinâmica. Recursos naturais e meio ambiente, Rio de J aneiro, IBGE, FIBGE/SUPREN, 1977. 97p.

VARGAS, M. Introdução à mecânica dos sol os. São Paulo, M cgrawHill do Brasil/EDUSP, 1977. 509p. 